\title{
Exploring plant tissue culture to improve the production of phenolic
}

\section{compounds: A review}

Maria Inês Dias ${ }^{\mathrm{a}, \mathrm{b}}$, Maria João Sousa ${ }^{\mathrm{a}}$, Rita C. Alves ${ }^{\mathrm{b}}$, Isabel C.F.R. Ferreira ${ }^{\mathrm{a},{ }^{*}}$

${ }^{a}$ Mountain Research Centre (CIMO), ESA, Polytechnic Institute of Bragança, Campus de Santa Apolónia, 1172, 5301-855 Bragança, Portugal.

${ }^{b}$ REQUIMTE/LAQV, Departamento de Ciências Químicas, Faculdade de Farmácia da Universidade do Porto, Rua Jorge Viterbo Ferreira, 228, 4050-313 Porto, Portugal.

*Author to whom correspondence should be addressed (e-mail: iferreira@ipb.pt telephone +351-273-303219; fax +351-273-325405). 


\section{Abstract}

Plant tissue and organ culture has been extensively used from the beginning of the XX century for the study and comprehension of some primary biological mechanisms such as morphogenesis. However, with the increasing demand of the market for novel products derived from plants, in vitro culture became a reliable technique for the mass production of plant material. Moreover, the potential to use this technique for the production of some bioactive compounds, such as phenolic compounds, is immense since it allows the manipulation of the biosynthetic routes to increase the production and accumulation of specific compounds. This work intends to make a brief historical review of in vitro culture, highlighting its use for the production of bioactive compounds. Also, emphasizes the importance of phenolic compounds for the consumer as well reviews the metabolic pathways involved in its production in plant cells. Furthermore, it was carried out a comprehensive study on the work developed for the production of plant phenolic compounds in in vitro cultures, as well as on the type of elicitors used to increase of the same production; also a brief highlighting of the phenolic compounds which serve as elicitors. There are numerous reports directed to the production of phenolic extracts in in vitro plant cultures, however there is a lack in the production of individual phenolic compounds mainly due to the complexity of the biosynthetic routes and extraction procedures. Elicitation procedures are often used to increase the production of phenolics, archieving in most cases higher yields than in nonelicitated cultures. The increasing production of bioactive phenolic extracts/compounds allows for their further applicability, namely in the industry of functional foods or in pharmaceutical/medical fields. 
Keywords: In vitro culture; Phenolic compounds; Biosynthetic routes; Metabolite production; Elicitation 


\section{Contents}

1. Introduction to plant tissue culture

1.1. Historical review

1.2. Benefits of using plant tissue culture

2. Phenolic compounds and elicitors

2.1. Added value of plants rich in phenolic compounds

2.2. Biosynthetic routes of plant phenolic compounds and the influence of elicitation

3. Improvement of phenolic compounds production

3.1. Production of phenolic compounds through plant tissue culture techniques

3.2. Improvement of plant tissue culture through the use of elicitors

\section{Concluding remarks}

Acknowledgements

References 


\section{Introduction to plant tissue culture}

\subsection{Historical review}

The history of plant tissue culture has been extensively described over the years, not only in specialized books and research articles, but also in biography papers of its most important intervenors such as Haberlandt, Gautheret, White, Murashige, Skoog, among others. In view of an updated description of in vitro culture, a brief historical review of this topic is presented in Fig. 1, in which the most striking points for the development of this technique are presented, focusing especially on the production of bioactive compounds of high interest. In 1902, Gottlieb Haberlandt proposed the first theoretical explanation for in vitro tissue culture based on the totipotency of plant cells, in which he tried to understand the functionality and relationships established by the cell in a multicellular organism. This study was performed by cultivating isolated plant cells in a nutrient solution (Loyola-Vargas and Vázquez-Flota, 2006). However, the first plant cell culture was only successfully developed in 1922 when Kolte and Robbins cultivated root and stem tips with the intention of overcoming the problem of medium sterilization (Kotte, 1922; Robbins, 1922).

The discovery of plant growth regulators, also known as plant hormones, was also a key-point that revolutionized the development of in vitro culture of plants by allowing to control, in a certain manner, the physiological process involved from germination to the formation of more specialized cells such as organs and tissues (Roberts, 2012). The first growth regulator discovered was indole-3-butyric acid (IAA), in 1926 by Went (Hussain et al., 2012).

In 1934-1935, Gautheret together with White and Nobercourt, developed the first "true" plant tissue culture since it involved the establishment of cambial tissue from Acer pseudoplatanus L. in a solidified medium combining knop's solution, glucose, 
cysteine, IAA and vitamins that lead to the differentiation of the tissues, obtaining an endless callus cultures proliferation (Gautheret, 1939). From that moment, different plants, organs and tissues but also different combinations of nutrient solutions were being tested in numerous trials. The decades between 1940 and 1960 are pointed out as one of the most important period for the development of the great majority of the techniques of plant tissue culture still used today. During that time many discoveries were made mainly in the field of plant growth regulators: kinetin was found in 1955 as a cell division hormone, leading Skoog and Miller in 1957 to arise the concept of hormonal control for organ formation by adjusting the concentration of auxins and cytokines in the medium (Skoog and Miller, 1957).

Nevertheless, the far most important revolutionizing step occurred during these decades was achieved by Murashige and Skoog in 1962, by developing the well-known MS (Murashige \& Skoog) medium for tobacco cell cultures that consisted of a high concentration of salts but low nitrogen, macro and micronutrients, a carbon source (e.g. sucrose), vitamins from the B complex and growth regulators (Murashige and Skoog, 1962). What they achieved by developing the MS medium was to combine all the nutritional requirements for a very large group of plants allowing its use, even nowadays, by many researchers in their in vitro plant culture studies (Loyola-Vargas and Vázquez-Flota, 2006).

In the following years many researchers continued to investigate the role of plant growth regulators in the development of in vitro plants (Loyola-Vargas and VázquezFlota, 2006; Hussain et al., 2012); furthermore, the totipotency of cell plants was demonstrated in increasingly smaller parts of the plant such as individual cells by Stewart in 1966 and protoplasts in 1970 by Tabeke (Loyola-Vargas and Vázquez-Flota, 2006). 
In terms of using plant tissue culture for the production of high valuable metabolites the first attempt occurred in 1950 by the Charles Pfizer Company with the intention of producing phytochemical compounds for the pharmaceutical industry using mould extracts from in vitro grown water-melons (Lombardino, 2010). However, the industrial applicability of plant tissue culture for the production of secondary metabolites was only considerable feasible in 1978 in German and Japan (LoyolaVargas and Vázquez-Flota, 2006). In 1987, the production of secondary metabolites by plant tissue culture techniques overcame the normal production of soil-grown plants, based on the results of more than 30 cell different culture systems, therefore, being considered an economical viable process for their production (Savangikar, 2004; Loyola-Vargas and Vázquez-Flota, 2006).

The immobilization protocols and "scale-up" techniques allowed the development of metabolite production systems commercially functional, being the production of vaccines and proteins for medical uses one out of the many applications (Kintzios, 2008). One of the most successful examples is the case of taxol and rosmarinic acid, used for their chemotherapeutic properties and antioxidant activity, respectively (Kintzios, 2008). The expansion of plant tissue culture continued to grow, being applied to an increasing number of plant species, and also in different fields. Nevertheless, for many researchers, it continued to be an important tool for the study of morphogenesis, primary metabolism and other physiological processes (Collin, 2001; Smetanska, 2008).

Although the concept of plant tissue culture began in the earlier XX century, the first articles published on the matter only appeared in the 20's decade (Fig. 2), and until the 60 's decade there was no progress by the academia in terms of publishable results. However, and as stated previously, it was in the $60^{\prime}$ s that the biggest thrust in plant 
tissue culture occurred, with the development of new techniques and culture media, and also with the discovery of the physiological importance of plant growth regulators. As it can be observed in Fig. 2, from the beginning of the 60's, it is noticeable an increase in articles and reviews regarding plant cell and tissue culture. In terms of industry, until the mid-80's, its interest was not significant when compared to the published work of academia, however, the number of patents related to plant cell and tissue culture overcame nowadays the number of published work by academia.

With this review article, it is intended to describe the main advantages of using plant tissue culture to produce high valuable bioactive compounds, dealing in particularly with phenolic compounds and their bioactive properties. Therefore, the production of these secondary metabolites in plant tissues and the biosynthetic routes involved in that production will be described. Furthermore, phenolic extracts and individual compounds produced by in vitro techniques will be revised as well as the elicitation techniques used to enhance their production.

\subsection{Benefits of using plant tissue culture}

The World Health Organization (WHO) estimates that $80 \%$ of the world population still depend nowadays on traditional medicinal to obtain primarily basic health care using it on a daily basis. Furthermore, two thirds of the anticarcinogenic and antiinfectious drugs, existing in the market, are derived from plants (Peter et al., 2005; Kolewe et al., 2008). With the unceasing market demand for products derived from natural matrices, an environmental concern emerges relatively to the loss of plant populations, genetic diversity, habitat degradation and, even, species extinction (Roberto et al., 2011). 
Plant cell and tissue culture emerges as a viable biotechnological tool for the production of bioactive compounds that can be used in the most diversified areas and particularly with a view of an additional effort for sustainable conservation and rational utilization of biodiversity (Karuppusamy, 2009). In 1994, the United Nations for Food and Agriculture (Food and Agriculture Organization- FAO) endorsed plant cell and tissue culture techniques as a process to produce natural compounds for food purposes (Anand, 2010; Roberto et al., 2011). In 2002, FAO published a report in association with IAEA (International Atomic Energy Agency - Division of Nuclear Techniques in Food and Agriculture) approaching the theme of in vitro culture techniques for the production of bioactive compounds with increased value, focusing on how they can be processed in the most economical way by researchers and industry (FAO/IAEA, 2002). Murthy et al. (2015) elaborated a security assessment on food ingredients derived from plant tissue and organ cultures, and proposed some protocols to evaluate toxicity of these products and also their potential bioactivity.

The broad definition of plant tissue and organ culture is the manipulation of cells and organs in aseptic conditions, grown in a culture medium under controlled conditions of light, humidity and temperature (Smetanska, 2008). This controlled production system allows the increasing of uniformity and standardization of the extracts, as such the concentration of the desired compounds, maintaining the same genetic characteristics of the highest production clones (Chaturvedi et al., 2007).

In theory, in vitro culture can be applied to any plant, since plant cells present in their genome the gene pool necessary to maintain their functions in an artificial medium, including secondary metabolism and totipotency. However, when foreseeing a future application, mainly industrial, the process viability is very important, but also the competitiveness of the methods used compared to existing ones (Verpoorte et al., 
1999). It is a very appealing technique for researchers and industry since it fixes two problems of soil-grown plants: the low growing rate dependent on climate conditions and low production yield of secondary metabolites. Specialized cells, shoots and roots grown in vitro can present a metabolic profile similar to native plants, this can also occur in non-specialized cells (Kolewe et al., 2008). The combination between biotechnology engineering process and biochemistry led to a significant improvement on production yields (Kolewe et al., 2008), highlighting the in vitro culture as the preferred method for the production of bioactive compounds (Zhou and $\mathrm{Wu}, 2006$ ). In fact, one example of biotechnology engineering process combined with biochemistry is the methodology of hairy root cultures, where the plant material is infected with Agrobacterium rhizogenes allowing greater genetic stability and growth, and consequently higher yields of bioactive compounds production, that are secreted to the medium, and easily extracted and purified (Anand, 2010). There are several advantages related with the in vitro production of bioactive compounds: optimized and controlled production conditions; final product control; selection of the best clones by genetic engineering; production of pure compounds; improvement of the nutritional effect of the plant produced; reduction of undesired compounds; free production of herbicides and pesticides; chemical synthesis of new compounds; production non-dependent on climatic and geographic conditions (Verpoorte et al., 1999; Chattopadhyay et al., 2002).

In vitro culture can be used, for example, to produce natural origin dyes to substitute chemical compounds with high toxicity, due to the increasing demand of the market. Anthocyanic compounds are natural dyes that when produced by in vitro culture techniques present higher quality without suffering degradation, either by storage or during extraction procedures (Zhang and Furusaki, 1999). Meristematic cultures can 
also be used for large-scale production of bioactive compounds, however its main purpose is for the multiplication of plants with high bioactive potential, since it is from these types of cells that new tissues and organs are formed (Lee et al., 2011). Ultimately, the greatest advantage of plant tissue and organ culture technique has been its ability to provide a continuous, sustainable, economical and viable production of natural compounds, regardless the geo-climatic conditions and under a microenvironment regime highly controlled (Karuppusamy, 2009; Anand, 2010).

\section{Phenolic compounds and elicitors}

\subsection{Added value of plants rich in phenolic compounds}

The bioactive properties of phenolic compounds are very well-known; countless research and review articles on this topic are available providing a thorough description of their biological and bioactive characteristics. Quideau et al. (2011), in their review article, performed a survey on the chemical and structural properties of many phenolics families, correlating them with the biological properties and the way they are expressed after consumption, in a daily basis, of fruits, vegetables, beverages, red wine and even chocolate. They came to the conclusion that, despite their poor solubility and bioavailability, these compounds can present beneficial health effects in a long-term when consumed in a daily basis, and that the chemical synthesis, serving the academic and industrial community, could provide analogue compounds that can be further introduced in food products. The phenolic compounds are nowadays among the most studied families of natural products, for their bioactive properties, being naturally produced by plants and showing an immense structural and chemical diversity. Many studies are still directed towards the biological and chemical structure, as well as the biosynthetic routes (e.g. enzymes involved in their production, genetic pool and 
proteins) (Boudet, 2007; Cohen and Kennedy, 2010). For all these reasons, the phenolic compounds became desirable targets for in vitro culture, which provides the necessary stress conditions for their production and increases the excretion of these secondary metabolites by the plant tissues (Matkowski, 2008). A special emphasis has been given to the production of anthocyanins for their recognized bioactive properties, but also because these pigments are easily degraded and polymerized under changes of $\mathrm{pH}$ (Zhang and Furusaki, 1999). In addition to their antioxidant properties, phenolic compounds are also being studied for their anticancer properties and ability to serve as natural food preservatives (Quideau et al., 2011; Carocho and Ferreira, 2013).

\subsection{Biosynthetic routes of plant phenolic compounds and the influence of elicitation}

In plants, a significant amount of carbon and energy are directed towards the production of molecules whose function is not completely clear. The central metabolism in plant cells is based on the respiratory pathways, glycolysis and the citric acid cycle, where the vast majority of molecules and compounds involved in plant survival and defense mechanisms are produced (Lobo and Lourenço, 2007). Phenolic compounds are usually produced as a defense mechanism against an attack on the plant tissue or in a stressful environment (e.g. unfavorable temperature, light and $\mathrm{pH}$ conditions). These compounds are refereed as secondary metabolites since they are not directly correlated with functions of growth and development of the plant tissue, and are normally found in particular tissues and organs and at particular stages of development of the plant (Buchanan and Jones, 2000). There are thousands of different phenolic compounds in terms of structure that will, by consequence, present several different biological activities depending also on the concentration in which they are consumed (Karakaya, 2004; Quideau et al., 2011). The basic structure of a phenolic compound is a benzene 
ring with hydroxyl substituent(s) (Cohen and Kennedy, 2010). In Fig. 3, a summary of the highly complex phenylpropanoid pathway is represented and the most important steps for the formation of some phenolic compounds are described. The most important pathway in the biosynthesis of phenolic compounds is the shikimic acid pathway in which one molecule of phosphoenolpyruvic acid (PEP) derived from glycolysis and erythrose-4-phosphate derived from the pentose phosphate pathway are combined resulting in the formation of a seven carbon sugar called DAHP (3-deoxy- $O$-arabinoheptulosonate phosphate), being then cyclized and reduced to form shikimate. The formation of shikimate is a critical branch for the formation of phenolic compounds. It is important to notice that the shikimic acid pathway is also involved in the formation of proteins, primary metabolites with essential roles in the plant tissues and for that manner competes directly in the formation of phenolic compounds (Karakaya, 2004; Cohen and Kennedy, 2010) From this structure occurs the formation of phenolic acids (e.g. protocatechuic acid and ellagic acid), simple phenols only possessing a carboxyl group and serving as precursors of other compounds (Cohen and Kennedy, 2010). Or it can lead to the formation of aromatic amino acids, phenylalanine, tyrosine and tryptophan beginning the phenylpropanoid pathway from this point on. The biosynthesis of the aromatic amino acids is an example of feedback mechanism, which means that a higher production towards tryptophan will induce the carbon flux towards the production of phenylalanine and tyrosine (Verpoorte et al., 1999). Metabolically this is very interesting since the production of more complex phenolics begins with the deamination of phenylalanine to cinnamic acid (directly towards the production of coumarins) and then the conversion into $p$-coumaric acid (also derived from tyrosine). From the production of $p$-coumaric acid it can lead to the formation of hydroxycinnamic acids such as caffeic acid, the latter being converted in its alcohol form plus the alcohol form 
or $p$-coumaric acid can both lead to the formation of lignin. By the action of CHS (chalcones synthase), CHI (chalcones isomerase) and F3H (flavanone-3-hydroxylase) enzymes, the $p$-coumaric acid is then converted to flavonols (e.g. quercetin) and flavan3-ols (directly towards the production of proanthocianidins and anthocyanins).

Although plants naturally produce phenolic compounds when placed in vitro, there are many situations where it is necessary to improve that production. Due to the brief stationary phase that in vitro cultured plants present, secondary metabolites are, in general, produced in very low yields (inhibition of the action of enzymes, normally presented in mature plants) (Michael and John, 1985). Elicitation is used to increase the production and accumulation of secondary metabolites by in vitro production systems, triggering morphological and physiological responses. This stimulation occurs in response to stress stimulus of signal compounds that activate the protective mechanisms of the plants (Rea et al., 2011). Chemical elicitation is achieved by plant growth regulators, signalling molecules and addition of precursor molecules. Physical elicitation is done through UV irradiation, pressure, electric field, concentration of heavy metals, $\mathrm{pH}$ and temperature. Microorganisms, fungi and bacteria, can function as biological elicitors (Mewis et al., 2011; Baenas et al., 2014). Fig. 3 also shows some points where elicitation can be used to increase the production of phenolic compounds; for example, the enzyme catalysing the reaction of deamination of phenylalanine into cinnamic acid is PAL (phenylalanine ammonia lease). The activity of this enzyme is stimulated by red and UV radiation (Boudet, 2007), thus being present in the in vitro culture as a physical elicitation. There is an ecological connection between the elicitation and the production of certain types of compounds depending on the purpose of these compounds in the plant tissues. For example, the production of anthocyanins is highly influenced by the amount of light (physical elicitation) incident on plant tissues, 
once these compounds serve as light absorbers and thus protecting the cells from the adverse effects (Dixon and Paiva, 1995; Zhang and Furusaki, 1999). The production of these compounds is also achieved by other type of physical elicitation, such as temperature and $\mathrm{pH}$, but also through precursor feeding and media optimization (chemical elicitation). The production of coumarins, for instance, is achieved through biological elicitation, by using microorganisms to induce their formation, since this type of compounds is related with the protection of plant tissues against pathogens' attack.

\section{Improvement of phenolic compounds production}

\subsection{Production of phenolic compounds through plant tissue culture techniques}

There are numerous studies on the production of secondary metabolites by using plant tissue culture, and several reviews that compile many of this information (Zhang and Furusaki, 1999; Chattopadhyay et al., 2002; Matkowski, 2008; Karuppusamy, 2009). However, the present review updates the available information, while focusing specifically on the production of phenolic compounds. Table 1 lists phenolic extracts and compounds produced by plant tissue culture, describing the part of the plant and the extraction solvent used to obtain them.

The production of phenolic compounds is the main goal of the vast majority of those studies (Andarwulan and Shetty, 1999; Lozovaya et al., 2000; Santos-Gomes et al., 2003; Gális et al., 2004; Lozovaya et al., 2006; Kouakou et al., 2007; Bairu et al., 2011; Cui et al., 2011; Krzyzanowska et al., 2011; Palacio et al., 2012; Szopa et al., 2013; Siu et al., 2014; Szopa and Ekiert, 2014; Yildirim and Turker, 2014). However, some of them are also focused on the study of the extract's bioactive properties, such as antioxidant (Grzegorczyk et al., 2007; Hakkim et al., 2007; Kovatcheva-Apostolova et al., 2008; Hussein et al., 2010; Amoo et al., 2012; Giri et al., 2012; Khateeb et al., 2012; 
Barros et al., 2013; Bhagya and Chandrashekar, 2013; Cheniany et al., 2013; Madhu, 2013; Goyali et al., 2014; Lugato et al., 2014; Piątczak et al., 2014; Valdez-Tapia et al., 2014), antimicrobial (Hussein et al., 2010; Ncube te al., 2011; Zhao et al., 2011; Khateeb et al., 2012) and cytotoxic (Skorić et al., 2012) activities.

As previously mentioned, anthocyanin extracts are appealing targets in studies regarding in vitro culture to obtain secondary metabolites. They are naturally occurring pigments in plants, fruits and vegetables with high antioxidant potential, also presenting some other biological activities such as antitumoral, anti-inflammatory and antimutagenic (Kong et al., 2003). Konczak-Islam et al. (2003) obtained high concentrations of acylated anthocyanin pigments from the calli of Ipomoea batatas L. cv. Ayamurasaki. Chlorogenic and caffeic acids were also identified as major phenolic compounds. On the other hand, Barros et al. (2012) detected anthocyanin's production in a clone of Coriandrum sativum L. vegetative parts in the same MS medium where other clones were produced, suggesting that the production of anthocyanin compounds could be affected by the environmental or physiological stress of in vitro culture conditions. Longo et al. (2007) performed the anthocyanin's characterization and production by shoots of Eugenia myrtifolia Sims, observing that this plant produced only a molecular form of malvidin, one of the most common anthocyanins in higher plants (Kong et al., 2003), which can be used as a model to study the biosynthetic pathway of these compounds.

Betalains are also pigments widely used as food colorants, presenting, in addition, high antioxidant potential due to the presence of phenolic hydroxy groups in their structure. Georgiev et al. (2010) studied the phenolic composition in betalain extracts secreted to the medium by hairy roots of Beta vulgaris cv. Detroit Dark Red, observing that these extracts presented higher antioxidant activity than the initial plant material, and 
concluding that the synergistic effects between betalains and the concomitant phenolic compounds may have caused that bioactivity. Dubravina et al. (2005) focused their study in the production of flavan compounds by calli of Taxus baccata L. and $T$. canadensis Marsh. for one year, noticing a significant increase of the production of these compounds during the summer season and also a change in the phenolic content during the differentiation of the tissues. Iwasa et al. (2010) produced phenolic tetrahydroprotoberberines by using calli tissue of Corydalis ochotensis var. Raddeane, Macleaya cordata $\mathrm{R} . \mathrm{Br}$ and Nandina domestica Thunb, to be used for its antimalarial activity.

Phenolic acids are another group of compounds with high phytochemical potential due to their biological activity. Thiem et al. (2013) studied the production of phenolic acids by hairy roots and shoots of Eryngium planum L., observing high levels of caffeic and chlorogenic acids, but most of all, rosmarinic acid secreted from the hairy roots (easier extraction procedure). Szopa and Ekiert (2012) found high levels of $p$-coumaric, $p$ hydroxybenzoic, protocatechuic, salicylic and syringic acids in calli from Schisandra chinensis (Turcz.) Baill., increasing the phytochemical value of this plant. Alemanno et al. (2003) in their study with staminodes and anthers of Theobroma cacao L., concluded that tissue culture is a reliable technique to maintain and multiply high producing clones of this plant, and identified three phenolic acids, hydroxycinnamic acid amides, that had never been found in original tissues.

All of the mentioned studies are referring to extracts that were further characterized in terms of phenolic compounds composition. However, there are many studies already focused on the production and subsequent extraction of individual phenolic compounds (Fig. 4). As previously mentioned, phenolic acids are a group of compounds that incites the researchers due to their bioactive properties. In fact, most of the studies on 
individual phenolic compounds obtained by tissue culture production involve phenolic acids. Chen et al. (1999) studied the production of lithospermic acid B (Fig. 4a) and rosmarinic acid (Fig. 4b) by hairy roots of Salvia miltiorrhiza Bunge, while Rady and Nazif (2005) described the production of rosmarinic acid in shoots of Ocimum americanum L. var pilosum. The aim was to increase the bioactive potential of plants traditionally used and for which the production capacity of these compounds through in vitro culture was unknown until then. o-Coumaric acid glucoside (Fig. $4 \mathrm{c}$ ) and cinnamic acid glucoside (Fig. 4d) were both produced in cell suspension of Rauwolffia serpentine Benth. E Kurz, to prove the glucosylating capacity of this plant (Schroeder et al.,1996). Schroeder et al. (1996) also isolated picein (Fig. 4e), a compound related with the mark of tree damage. Sircar et al. (2007) used the hairy root system to produce $p$ hidroxybenzoic acid (Fig. 4f) in Daucus carota L., showing that the accumulation of this compound occurred in the cytosol and in the cell wall, being a promising sample to study the biosynthetic pathway of this compound. On the other hand, 3,5-Ocaffeoylquinic and 5-O-caffeoylquinic acids (Fig. 4g) was produced by plantlets and calli from Solidago graminifoli L. and Solidago virgaurea L., plants with important traditional use in Poland and used widely by the population for their medicinal characteristics that can be attributed to the presence of phenolic acids (Thiem et al., 2001). In the same study a phenolic ester glucoside, leiocoposide (Fig. 4h), was also isolated, being interesting to be produced in large quantities due to its urological activity (Thiem et al., 2001).

With less numerical significance, but with high bioactive importance, the class of flavonoids, especially flavones, have also been targeted to be produced and isolated from in vitro culture systems. Nishikaw et al. (1999) produced a flavone derivative (Fig. 4i, 5,2'-dihydroxy-6,7,8,3'-tetramethoxyflavone) by using a hairy root system of 
Scutellaria baicalensis Georgi, whose roots are traditionally used for the treatment of hepatitis, tumor, diarrhea and inflammatory diseases. Shinde et al. (2010) isolated an isoflavone from the calli culture of Psoralea corylifolia L. and tested its antioxidant activity, which was higher under continuous illumination. On the other hand, Yang et al. (2001) isolated an isoflavone (Fig. 4j) from the calli of Mirabilis jalapa L., revealing antifungal activity against Candida albicans. In this study, a second compound was isolated (dehydrorotenoid Fig. 4k) also showed antifungal activity. Ziaratnia et al. (2009) isolated a new chlorophenol (Fig. 41) compound from the calli culture of Helichrysum aureonitens L. Moench, revealing antitumoral and antituberculosis activities. At last, Pinhatti et al. (2010) isolated two phenolic compounds from the aerial part of Hypericum ternum A. St Hill, hyperoside and uliginosin (Fig. 4m), founding that the levels produced in vitro were significantly higher than the ones found in wild plants.

\subsection{Improvement of plant tissue culture through the use of elicitors}

Elicitation is used in order to increase the production and accumulation of secondary metabolites by in vitro production systems. The main elicitor groups used in the improvement of phenolic production by plant tissue culture systems are shown in Table 2. The biological elicitation in plant tissue culture systems is based, as previously mentioned, on the inoculation of bacteria and fungi strains that stimulate the phenylpropanoid pathway as a response to the microbial attack, improving the production of phenolic compounds and, in some cases, achieving higher biomass production (Al-Amier et al., 1999; Verpoorte et al., 1999). In terms of bacteria strains, Pseudomonas sp. are the most used, leading to higher production yields of rosmarinic acid in clonal lines of Lavandula angustifolia Mill. (Al-Amier et al., 1999) and Rosmarinus officinlis L. (Yang et al., 1997) shoots. It also increased the production of 
phenolic compounds in Thymus vulgaris L. shoots (Shetty et al., 1996). In all of these studies, a higher shoot formation in the selected clonal lines was observed, leading to higher biomass production. Many elicitation studies, a part of the objective of obtaining higher production of phenolic compounds, are performed in order to understand the mechanism of plant resistance against fungi. Alami et al. (1998) studied the production of hydroxycoumarin phytoalexins, phenolic compounds involving in the disease resistance, by calli of Platanus acerifolia Aiton elicitated with Ceratocystis fimbriata $\mathrm{f}$. sp. platani. The authors concluded that a glycoprotein from the fungus induced the production of $80 \%$ of coumarins, being released to the growth culture medium. Xanthone production increased tenfold in cell culture of Hypericum perfuratum L. after elicitation with Colletotrichum gloeosporioides (Conceição et al., 2006). The same happened with hydroxycinnamic derivatives in calli culture of Phoenix dactylifera L. elicitated with Fusarium oxysporum f. sp. albedinis (Daayf et al., 2003). These two studies demonstrate that plants produce an enormous amount of phenolic compounds as a defence mechanism against fungus attack. In Nicotina tabacum L. cell culture after elicitation with Phythophtora megasperma f. sp. glycinea, it was observed an increase of cell-wall bonded phenolics (Ikemeyer and Barz, 1989). Hrazdina (2003) observed a differential production of phenolic compounds in leaves and stems produced by in vitro culture of Malus domestica Borkh cv. Liberty and cv. McIntos elicitated with yeast extract and Venturia inaequalis (fungus). In a study carried out by Vuković et al. (2013) the fungus was not added directly to the cultured plant; instead, a genetic transformation was performed using Agrobacterium rhizogenes carrying a gene encoding $\beta$-cryptogein (produced by Phytophthora cryptogea) which mimics the attack of a pathogen, inducing a mechanism defense from the plant, resulting in higher phenolic concentration in the cultured medium, mainly rosmarinic and caffeic acids. 
Chemical elicitation can be achieved by triggering physiological and morphological responses by adding to the medium chemical compounds that interfere with the biosynthetic routes that lead to the production of phenolic compounds (Dong et al., 2010). In fact, many of the precursors of secondary metabolism (phenylpropanoid pathway) are derived from the primary metabolism, targeting equilibrium between growth and defence (Lattanzio et al., 2009). There are numerous chemical elicitors: amino acids, organic compounds, plant growth regulators and even precursors of some polyphenols. Proline is one of the most used amino acids as an elicitor for the production of phenolic compounds, and was used by Lattanzio et al. (2009) and Yang and Shetty (1998) in shoots and calli and aerial parts, respectively, of in vitro cultured Origanum vulgare L. In both studies, proline was found to stimulate the pentose phosphate pathway that directs towards the shikimate and phenylpropanoid pathway, being observed a higher accumulation of phenolic compounds, such as rosmarinic, caffeic and litosphermic acids (Yang and Shetty, 1998; Lattanzio et al., 2009). Casein hydrolysate and L-phenylalanine have also been used to induce the production of phenolics in calli of Ephedra alata Decne., being noticed a higher accumulation of chlorogenic acid, rutin, catechin, quercetin and coumaric acid in calli elicitated with casein hydrolysate (Hegazi and El-Lamey, 2011).

In terms of organic elicitation, salicylic acid and jasmonic acid are two of the examples that have been used to induce the production of phenolic compounds by in vitro cultures, being signalling molecules of different pathways. While jasmonic acid is involved in the activation of the octadecanoid signalling pathway, salicylic acid induces the phenylpropanoid signalling, however, both respond to mechanical or chemical attacks against the plant (Mewis, 2011). Salicylic acid proved to stimulate the activity of PAL enzymes on calli of Salvia miltiorrhiza Bunge leading to the accumulation of 
salvianolic acid B and caffeic acid (Dong et al., 2010). It has also been proved that salicylic acid improves biomass production and anthocyanin concentration in calli and cell cultures of Vitis vinifera L. cv. Gamay Fréaux (Mewis, 2011). Sometimes compounds that are normally used as herbicides can also function as elicitors under in vitro culture. An example is the glyphosate compound used to enhance phenolic compounds production in calli culture of Zea mays L., causing an accumulation of shikimic and quinic acids (Ulanov et al., 2009). Some organic elicitors can also function in the other way, inhibiting the production of phenolic compounds to prevent some common problems related with the presence of this type of compounds in vitro, such as browning (leads to cell death). That was the work developed by Jones and Saxena (2012), that used 2-aminoindane-2-phosphonic acid to inhibit the phenylpropanoid pathway in calli of Acer saccharum Marsh., Artemisia annua L. and Ulmus Americana L. Chemical elicitation also involves the use of precursor molecules that will induce the production of phenolic derivatives of the precursor. Rao et al. (1996) used phycocyanin in calli of Capsicum frutescens L. and Daucus carota L. producing two times more capsaicin and anthocyanin, respectively, than the original culture. However, most of the investigations on precursors are directed to other type of studies, such as the precursor feeding to calli of Catharanthus roseus L. to determine the glycosylation and hydroxylation capacity of this plant (Shimoda et al., 2003). In another study, the precursor of anthocyanin compounds labelled with phenylalanine was used to mark the anthocyanin production in Vitis vinifera cv. Gamay Red calli (Krisa et al., 1999). The genetic induction is also a part of chemical elicitation, especially transcription factors that allow the control of specific proteins involved in the biosynthesis of phenolic compounds. Dias and Grotewold (2003) induced the transcription factor ZmMyb-IF35 
for the R2R3 Myb genes in cell culture of Zea mays L., noticing an accumulation of ferulic and chlorogenic acids that were not present in the control sample.

Plant hormones revolutionized plant tissue culture, mainly due to the fact that a balance between two or more hormones can induce the growth of different organs and cells in the plants. However, plant growth regulators can also be used to induce chemical elicitation and improve phenolic compounds production. Cytokins were used as elicitors in aerial parts and roots of Merwilla plumbea (Lindl. Speta (Aremu et al., 2013) and in calli of Vitis vinifera L. (Ozden and Karaaslan, 2011), conducting to a significantly higher production of phenolic compounds, and especially vannilic acid, in M. plumbea. After testing several distinct plant growth regulators in different concentrations and groups, Luczkiewicz et al. (2014) also observed a higher production of isoflavones in calli of Genista tinctoria L. elicitated with cytokins.

Finally, physical elicitation can be achieved, as chemical elicitation, with abiotic factors, that don't have a biological origin. It represents a consistent alternative for large-scale applications, since allows repeated applications without contaminating the bioactive compounds and the plant culture (Rea et al., 2011). Some compounds used for physical elicitation are chemical compounds, such as cadmium, copper and magnesium. Cadmium was applied in calli culture of Camellia sinensis L. to study the metabolic changes caused by this heavy metal, observing a noticeable change in lignin and flavanoids composition in the tea plant culture (Zagoskina et al., 2007). Copper was used to enhance the production of phenolic compounds in root culture of Panax ginseng, increasing up to $76 \%$ the production of phenolics and flavonoids (Ali et al., 2006). Similar results were found in cell culture of Vitis vinifera cv. Gamay Red, where the application of magnesium to the culture increased four times more the anthocyanin accumulation (Sinilal et al., 2011). Different light intensities have also been used to 
induce physical elicitation. Once light is one of the most stressful factors for plant growth, phenolic compounds emerged as active UV filters. The photoreceptors involved in the light-dependent development of plants include a family of flavoproteins (cryptochromes) that caused a wide range of morpho-anatomical responses, including the production of phenolic compounds (Victório et al., 2011). Arezki et al. (2001) verified that a simple change to a $16 \mathrm{~h}$ photoperiod increased the content of phenolic compounds in aerial parts of Eucalyptus camaldulensis Dehn. The most commonly used spectrum for UV light is B, however, Victório et al. (2011) verified that the UV-A light increased the content of ellagic acid and ellagitannin derivatives, but also caused a reduction in the number of branches and shoots of Phyllanthus tenellus L. Kwon et al. (2009) and Zagoskina et al. (2003) verified an increase of the phenolic content in shoots of Origanum vulgare L. and calli of Camellia sinensis L. Georgian, respectively, after treatment with UV-B light without any damage to the tissues. On other hand, Zagoskina et al. (2005) verified that the phenolic compounds increased to a certain subculture day after UV-B light elicitation, decreased, and then increased again, in calli from Camellia sinensis L, concluding that the UV light dependent production of phenolic compounds is much more complex, noticing also a decrease in cell calli size. Little is known about pulsed electric field on tissue culture protocols; however, it has been used in the food industry to eliminate microorganisms. Since it is a stress factor to plant cells, it has been purposed to elicitate the production of secondary metabolites. Cai et al. (2001b) studied the effect of pulsed electric field combined with a plant growth regulator on cell culture of Vitis vinifera cv. Gamay Fréaux, and obtained higher yields of anthocyanin and phenolic compounds production than in the control sample.

Sometimes elicitation procedures are combined to increase the process efficiency. One of the most common examples of combined elicitation is the test between different 
growth regulators and nutritional components of the basal medium. Examples of that are the studies performed by Kikowska et al. (2014) with shoots and roots of Eryngium maritimum L., and by North et al. (2012) with aerial parts of Strelitzia reginae Banks. Another study carried out by Stanly et al. (2011) with calli of Zingiber zerumbet Smith, showed that the combination of 2,4-D, kinetin, picloram, 1-naphthaleneacetic acid, sucrose and light photopheriod increase the antioxidant compounds produced. Sharan et al. (1998) studied the production of coumarin compounds (scopoletin and scopolin) in cell culture of Nicotina tabacum L. elicitated with the pathogenic fungus Fusarium solani f.sp. robiniae and also methyl jasmonate. The authors observed that the response was different, and the accumulation of coumarins was higher with methyl jasmonate, which is in accordance with the previously mentioned result that pathogen attacks could increase the production of coumarin compounds. Baskaran et al. (2012) and Baskaran et al. (2014) studied the effects of various elicitors in shoots and roots of Merwilla plumbea (Lindl.) Speta and aerial parts of Coleonema pulchellum L. Williams, respectively. The elicitors used were different growth regulators, amino acids and even yeast extract. In M. plumbea culture, the production of phenolics were around 3- to 16fold higher than in naturally-grown plants. On the other hand, C. pulchellum culture showed higher antibacterial activity with combined elicitors. In the study performed by Abraham et al. (2011) with shoot culture of Curcuma manga Valeton and van Zijp, the authors combined yeast extract and chitosan and observed a higher yield of antioxidant compounds.

Cai et al. (2001a) went even further and combined streptomycin, activated charcoal, ethephon and hydrostatic pressure to enhance the phenolic compounds production in cell culture of Vitis vinifera L. cv. Gamay Fréaux, observing that the concentration of 
phenolic acids was higher than in the control, but the biomass and anthocyanin production was not affected.

At this point, it is important to highlight that phenolic compounds can also be used themselves as elicitors. From the knowledge of the biosynthetic pathways of phenylpropanoid compounds, researchers come to realize that the exogenous addition of precursors or intermediates of phenolic compounds may induce or increase the yield of the desired compounds (Palacio et al., 2011). Table 3 summarizes the information regarding studies where phenolic compounds were used as elicitors. Lorenzo et al. (2001) studied the effect of adding gallic acid to a shoot culture of sugarcane (Saccharum sp.) and realized that, combined with indolacetic acid and cysteine, it promoted the phenolic excretion to the medium. Palacio et al. (2011) used cinnamic, ferulic and sinapic acids as precursors feeding in calli culture of Larrea divaricata Cav. Otherwise, Arencibia et al. (2008) studied the action of phenolic metabolites in the induction of genes from the phenylpropanoid pathway in aerial parts of Saccharum officinarum spp., cv. Badila. In both cases further studies are needed to establish the connection between elicitation and production of phenolic compounds. Other studies used phenolics as growth promoters and, consequently, achieving higher biomass, namely the studies conducted by Franklin and Dias (2011) and Reis et al. (2008) in cell culture of Hypericum perfuratum L. and zygotic embryos of Feijoa sellowiana Berg, respectively.

\section{Concluding remarks}

The in vitro culture is a very attractive technique for the cultivation of secondary metabolites, particularly phenolic compounds. Being an alternative to the production of plant in soil, it is also an ecological and sustainable alternative for the production of 
plant species at risk (overexploitation and extinction), but with high bioactive potential. It should be noted that this technique has also been endorsed by FAO as safe for the production of compounds for food application.

The complexity of phenolic compounds is in accordance with the complexity of their biosynthetic pathways; nevertheless it can be manipulated by researchers through elicitation in order to increase the production of certain molecules. The majority of the studies involve phenolic extracts and the corresponding bioactivities. Studies with individual phenolic compounds are still scarce, especially due to the complexity of producing such compounds and also the extraction and isolation procedures involved.

Plant cell and tissue culture allows, in general, higher yields of the phenolic extracts/compounds, however, the elicitation of cultures is required in order to achieve even higher production. There are different types of elicitation, chemical, biological and physical, being chemical elicitation the most widely used, especially growth regulators and addition of precursors. The combination of various types of elicitors is also used to obtain higher amounts of phenolic compounds by in vitro cultures.

The increasing production of bioactive phenolic extracts/compounds allows their further application, namely in the industry of functional foods or in pharmaceutical/medical field, as it is the case of the previously mentioned taxol and rosmarinic acid, used for their chemotherapeutic properties and antioxidant activity, respectively.

\section{Acknowledgements}

The authors are grateful to Fundação para a Ciência e a Tecnologia (FCT, Portugal) for financial support to CIMO (strategic project PEst-OE/AGR/UI0690/2014) and M.I. Dias grant (SFRH/BD/84485/2012). This work received financial support from the European Union (FEDER funds through COMPETE) and National Funds (FCT) 
through project UID/QUI/50006/2013, and FEDER funds under the framework of QREN through Project NORTE-07-0124-FEDER-000069. 


\section{References}

Abraham, F., Bhatt, A., Keng, C.L., Indrayanto, G., Sulaiman, S.F., 2011. Effect of yeast extract and chitosan on shoot proliferation, morphology and antioxidant activity of Curcuma mangga in vitro plantlets. Afr. J. Biotechnol. 10, 7787-7795.

Alami, I., Mari, S., Clérivet, A., 1998. A glycoprotein from Ceratocystis fimbriata f. sp. platani triggers phytoalexin synthesis in Platanus $\times$ acerifolia cell-suspension cultures. Phytochemistry. 48, 771-776.

Al-Amier, H., Mansour, B.M.M., Toaima, N., Korus, R.A., Shetty, K., 1999. Tissue culture based screening for selection of high biomass and phenolic producing clonal lines of lavender using Pseudomonas and azetidine-2-carboxylate. J. Agric. Food Chem. 47, 2937-2943.

Alemanno, L., Ramos, T., Gargadenec, A., Andary, C., Ferriere, N. 2003. Localization and identification of phenolic compounds in Theobroma cacao L. somatic embryogenesis. Ann. Bot. 92, 613-623.

Ali, M.B., Singh, N., Shohael, A.M., Hahn, E.J., Paek, K. 2006. Phenolics metabolism and lignin synthesis in root suspension cultures of Panax ginseng in response to copper stress. Plant Sci. 171, 147-154.

Amoo, S.O., Aremu, A.O., Staden, J.V. 2012. In vitro plant regeneration, secondary metabolite production and antioxidant activity of micropropagated Aloe arborescens Mill. Plant Cell Tiss. Org. Cul. 111, 345-358.

Anand, S., 2010. Various approaches for secondary metabolite production through plant tissue culture. Pharmacia 1, 1-7.

Andarwulan, N., Shetty, K., 1999. Phenolic content in differentiated tissue cultures of untransformed and Agrobacterium-Transformed Roots of Anise (Pimpinella anisum L.). J. Agric. Food Chem. 47, 1776-1780.

Aremu, A.O., Gruz, J., Šubrtová, M.,Szüčová, L., Doležal, K., Bairu, M.W., Finnie, J.F., Staden, J.V. 2013. Antioxidant and phenolic acid profiles of tissue cultured and acclimatized Merwilla plumbea plantlets in relation to the applied cytokinins. J. Plant Physiol. 170, 1303-1308.

Arencibia, A.D., Bernal, A., Yang, L., Cortegaza, 1., Carmona, E.R., Pérez, A., Hua, C., Li, Y., Zayas, C.M., Santana, I. 2008. New role of phenylpropanoid compounds during sugarcane micropropagation in Temporary Immersion Bioreactors (TIBs). Plant Sci. 175, 487-496. 
Arezki, O., Boxus, P., Kevers, C., Gaspar, T. 2001. Changes in peroxidase activity, and level of phenolic compounds during light-induced plantlet regeneration from Eucalyptus camaldulensis Dehn. nodes in vitro. Plant Growth Regul. 33, 215-219.

Arora, J., Goyal, S., Ramawat, K.G. 2010. Enhanced stilbene production in cell cultures of Cayratia trifolia through co-treatment with abiotic and biotic elicitors and sucrose. In Vitro Cel. Dev.B. 46, 430-436.

Baenas, N., García-Viguera, C., Moreno, D.A. 2014. Elicitation: A tool for enriching the bioactive composition of foods. Molecules 19, 13541-13563.

Bairu, M.W., Amoo, S.O., Staden, J.V., 2011. Comparative phytochemical analysis of wild and in vitro-derived greenhouse-grown tubers, in vitro shoots and callus-like basal tissues of Harpagophytum procumbens. S. Afr. J. Bot. 77, 479-484.

Barros, L., Dueñas, M., Dias, M.I., Sousa, M.J., Santos-Buelga, C., Ferreira, I.C.F.R. 2012. Phenolic profiles of in vivo and in vitro grown Coriandrum sativum L. Food Chem. 132, 841-848.

Barros, L., Dueñas, M., Dias, M.I., Sousa, M.J., Santos-Buelga, C., Ferreira, I.C.F.R. 2013. Phenolic profiles of cultivated, in vitro cultured and commercial samples of Melissa officinalis L. infusions. Food Chem.136, 1-8.

Baskaran, P., Moyo, M., Staden, J.V. 2014. In vitro plant regeneration, phenolic compound production and pharmacological activities of Coleonema pulchellum. S. Afr. J. Bot. 90, 74-79.

Baskaran, P., Ncube, B., Staden, J.V., 2012. In vitro propagation and secondary product production by Merwilla plumbea (Lindl.) Speta. Plant Growth Regul. 67, 235245.

Bhagya, N. and Chandrashekar, K.R., 2013. Evaluation of plant and callus extracts of Justicia gendarussa Burm. F. for phytochemicals and antioxidant activity. Int. J. Pharm. Pharm. Sci., 5, 82-85.

Boudet, AM. 2007. Evolution and current status of research in phenolic compounds. Phytochemistry. 68, 2733-2735.

Buchanan, B.B and Jones, R.L., 2000. Biochemistry \& Molecular biology of plants. Vol. 40. Rockville, MD: American Society of Plant Physiologists.

Cai, Z., Riedel, H., Saw, N.M.M.T., Mewis, I., Reineke, K., Knorr, D., Smetanska, I., 2011a. Effects of elicitors and high hydrostatic pressure on secondary metabolism of Vitis vinifera suspension culture. Process Biochem. 46, 1411-1416. 
Cai, Z., Riedel, H., Saw, N.M.T.T., Kütük, O., Mewis, I., Jäger, H., Knorr, D., Smetanska, I., 2011b. Effects of pulsed electric field on secondary metabolism of Vitis vinifera L. cv. Gamay Fréaux suspension culture and exudates. App. Biochem. Biotechnol. 164, 443-453.

Carocho, M. and Ferreira. I.C.F.R., 2013. A review on antioxidants, prooxidants and related controversy: natural and synthetic compounds, screening and analysis methodologies and future perspectives. Food Chem. Toxicol. 51, 15-25.

Chattopadhyay, S., Farkya, S., Srivastava, A.K., Bisaria, V.S., 2002. Bioprocess considerations for production of secondary metabolites by plant cell suspension cultures. Biotechnol. Bioproc. Eng. 7, 138-149.

Chaturvedi, H.C., Jain, M., Kidwai, N.R., 2007. Cloning of medicinal plants through tissue culture- A review. Indian J. Exp. Biol. 45, 937-948.

Chen, H., Chen, F., Zhang, Y.L., Song, J.Y., 1999. Production of lithospermic acid B and rosmarinic acid in hairy root cultures of Salvia miltiorrhiza. J. Ind. Micro. Biotechnol. 22, 133-138.

Cheniany, M., Ebrahimzadeh, H., Vahdati, K., Preece, J.E., Masoudinejad, A., Mirmasoumi, M., 2013. Content of different groups of phenolic compounds in microshoots of Juglans regia cultivars and studies on antioxidant activity. Acta Physiol. Plant. 35, 443-450.

Cohen, S.D. and Kennedy, J.A., 2010. Plant metabolism and the environment: Implications for managing phenolics. Crit. Rev. Food Sci. Nutr. 50, 620-643.

Collin, H.A. 2001. Secondary product formation in plant tissue cultures. Plant Growth Regul. 34, 119-134.

Conceição, L.F.R., Ferreres, F., Tavares, R.M., Dias, A.C.P., 2006. Induction of phenolic compounds in Hypericum perforatum L. cells by Colletotrichum gloeosporioides elicitation. Phytochemistry. 67, 149-155.

Cui, X., Murthy, H.N., Jin, Y., Yim, Y., Kim, J., Paek, K. 2011. Production of adventitious root biomass and secondary metabolites of Hypericum perforatum L. in a balloon type airlift reactor. Bioresource Technol. 102, 10072-10079.

Daayf, F., Bellaj, M.E., Hassni, M.E., J'Aiti, F., Hadrami, I.E., 2003. Elicitation of soluble phenolics in date palm (Phoenix dactylifera) callus by Fusarium oxysporum f. sp. albedinis culture medium. Environ. Exp. Bot. 49, 41-47. 
Danova, K., Čellárová, E., Macková, A., Daxnerová, Z., Kapchina-Toteva, V., 2010. In vitro culture of Hypericum rumeliacum Boiss. and production of phenolics and flavonoids. In Vitro Cel. Dev. B. 46, 422-429.

Dias, A.P., Grotewold, E., 2003. Manipulating the accumulation of phenolics in maize cultured cells using transcription factors. Biochem. Eng. J. 14, 207-216.

Dixon, R.A. and Paiva, N.L., 1995. Stress-lnduced Phenylpropanoid Metabolism. The Plant Cell 7, 1085-1097.

Dong, J., Wan, G., Liang Z., 2010. Accumulation of salicylic acid-induced phenolic compounds and raised activities of secondary metabolic and antioxidative enzymes in Salvia miltiorrhiza cell culture. J. Biotechnol. 148, 99-104.

Dubravina, G.A., Zaytseva, S.M., Zagoskina, N.V., 2005. Changes in formation and localization of phenolic compounds in the tissues of European and canadian yew during dedifferentiation in vitro. Russ. J. Plant Physiol. 52, 672-678.

FAO/IAEA Division of Nuclear Techniques in Food and Agriculture, 2002. Low cost options for tissue culture technology in developing countries. Proceedings of a Technical Meeting, Viena.

Franklin, G. and Dias, A.C.P., 2011. Chlorogenic acid participates in the regulation of shoot, root and root hair development in Hypericum perforatum. Plant Physiol. Biochem. 49, 835-842.

Gális, I., Kakiuchi, Y., Šimek, P., Wabiko, H., 2004. Agrobacterium tumefaciens AK$6 \mathrm{~b}$ gene modulates phenolic compound metabolism in tobacco. Phytochemistry. $65,169-179$.

Gautheret, R. 1939. Sur la possibilité de réaliser la culture indéfinie des tissues de tubercules de carotte. C. R. Soc. Biol. 208, 118-120.

Georgiev, V.G., Weber, J., Kneschke, E., Denev, P.N., Bley, T., Pavlov, A.I., 2010. Antioxidant activity and phenolic content of betalain extracts from intact plants and hairy root cultures of the red Beetroot Beta vulgaris cv. Detroit Dark Red. Plant Food. Hum. Nutr. 65, 105-111.

Giri, L., Dhyania, P., Rawata, S., Bhatta, I.D., Nandia, S.K., Rawala, R.S., Pande, V., 2012. In vitro production of phenolic compounds and antioxidant activity in callus suspension cultures of Habenaria edgeworthii: A rare Himalayan medicinal orchid. Ind. Crop. Prod. 39, 1-6.

Goyali, J.C., Igamberdiev, A.U., Debnath, S.C., 2013. Morphology, phenolic content and antioxidant capacity of lowbush blueberry (Vaccinium angustifolium Ait.) 
plants as affected by in vitro and ex vitro propagation methods. Can. J. Plant Sci. 93, 1001-1008.

Grzegorczyk, I., Matkowski, A., Wysokińska, H., 2007. Antioxidant activity of extracts from in vitro cultures of Salvia officinalis L. Food Chem. 104, 536-541.

Güllüce, M., Sökmen, M., Daferera, D., Ağar, G., Özkan, H., Kartal, N., Polissiou, M., Sökmen, A., Șahin, F., 2003. In vitro antibacterial, antifungal, and antioxidant activities of the essential oil and methanol extracts of herbal parts and callus cultures of Satureja hortensis L. J. Agric. Food Chem. 51, 3958-3965.

Hakkim, F.L., Shankar, C.G., Girija, S., 2007. Chemical composition and antioxidant property of holy basil (Ocimum sanctum L.) leaves, stems, and inflorescence and their in vitro callus cultures. J. Agric. Food Chem. 55, 9109-9117.

Hegazi, G.A.E. and El-Lamey, T.M., 2012. In vitro production of some phenolic compounds from Ephedra alata Decne. JAEBS 1, 158-163.

Hrazdina, G. 2003. Response of scab-susceptible (McIntosh) and scab-resistant (Liberty) apple tissues to treatment with yeast extract and Venturia inaequalis. Phytochem. 64, 485-492.

Hussain, A., Qarshi, I.A., Nazir, H., Ullah, I., 2012. Plant Tissue Culture: Current Status and Opportunities, Recent Advances in Plant in vitro Culture, Annarita Leva (Ed.), ISBN: 978-953-51-0787-3, InTech, DOI: 10.5772/50568.

Hussein, E.A., Taj-Eldeen, A.M., Al-Zubari, A.S., Elhakimi, A.S., Al-Dubaie, A.R., 2010. Phytochemical screening, total phenolics and antioxidant and antibacterial activities of callus from Brassica nigra L. hypocotyl explants. Int. J. Pharm. 6, 464-471.

Ikemeyer, D., Barz, W., 1989. Comparison of secondary product accumulation in photoautotrophie, photomixotrophie and heterotrophie Nicotiana tabacum cell suspension cultures. Plant Cell Rep. 8, 479-482.

Iwasa, K., Cui, W., Takahashi, T., Nishiyama, Y., Kamigauchi, M., Koyama, J., Takeuchi, A., Moriyasu, M., Takeda, K., 2010. Biotransformation of phenolic tetrahydroprotoberberines in plant cell cultures followed by LC-NMR, LC-MS, and LC-CD. J. Nat. Prod. 73, 115-122.

Jones, A.M.P. and Saxena, P.K., 2010. Inhibition of phenylpropanoid biosynthesis in Artemisia annua L.: A novel approach to reduce oxidative browning in plant tissue culture. PLoS One 8, 76802. 
Karakaya, S., 2004. Bioavailability of phenolic compounds. Crit. Rev. Food Sci. Nutr. $44,453-464$.

Karuppusamy, S., 2009. A review on trends in production of secondary metabolites from higher plants by in vitro tissue, organ and cell cultures. J. Med. Plant. Res. 3, 1222-1239.

Khateeb, W.A., Hussein, E., Qouta, L., Alu'datt, M., Al-Shara, B., Abu-Zaiton, A., 2012. In vitro propagation and characterization of phenolic content along with antioxidant and antimicrobial activities of Cichorium pumilum Jacq. Plant Cell, Tiss. Org. 110, 103-110.

Kikowska, M., Thiem, B., Sliwinska, E., Rewers, M., Kowalczyk, M., Stochmal, A., Oleszek, W., 2014. The effect of nutritional factors and plant growth regulators on micropropagation and production of phenolic acids and saponins from plantlets and adventitious root cultures of Eryngium maritimum L. J. Plant Growth Regul. $33,809-819$.

Kintzios, S., 2008. Secondary metabolite production from plant cell cultures: the success stories of rosmarinic acid and taxol. In: Bioactive Molecules and Medicinal Plants, Ramawat KG, Mérillon JM (eds.), Chapter 4, DOI: 10.1007 / 978-3-540-74603-4_4.

Kolewe, M.E., Gaurav, V., Roberts, S.C., 2008. Pharmaceutically active natural product synthesis and supply via plant cell culture technology. Mol. Pharm. 5, 243-256.

Konczak, I., Terahara, N., Yoshimoto, M., Nakatani, M., Yoshinaga, M., Yamakaw, O., 2005. Regulating the composition of anthocyanins and phenolic acids in a sweetpotato cell culture towards production of polyphenolic complex with enhanced physiological activity. Trends Food Sci. Tech.16, 377-388.

Konczak-Islam, I., Okuno, S., Yoshimoto, M., Yamakawa, O., 2003. Composition of phenolics and anthocyanins in a sweet potato cell suspension culture. Biochem. Eng. J. 14, 155-161.

Kong, J., Chia, L., Goh, N., Chia, T., Brouillard, R., 2003. Analysis and biological activities of anthocyanins. Phytochemistry. 64, 923-933.

Kotte, W., 1922. Kulturversuch isolierten Wurzelespitzen. Beitr. Allg. Bot. 2, 413-434.

Kouakou, T.H., Waffo-Téguo, P., Kouadio, Y.J., Valls, J., Richard, T., Decendit, A., Mérillon, J., 2007. Phenolic compounds and somatic embryogenesis in cotton (Gossypium hirsutum L.). Plant Cell Tiss. Org. 90, 25-29. 
Kovatcheva-Apostolova, E.G., Georgiev, M.I., Ilieva, M.P., Skibsted, L.H., Rødtjer, A., Andersen, M.L., 2008. Extracts of plant cell cultures of Lavandula vera and Rosa damascena as sources of phenolic antioxidants for use in foods. Eur. Food Res. Technol. 227, 1243-1249.

Krisa, S., Téguo, P.W., Decendit, A., Deffeux, G., Vercauteren, J., Mérillon, J., 1999. Production of $13^{\mathrm{C}}$-labelled anthocyanins by Vitis vinifera cell suspension cultures. Phytochemistry. 51, 651-656.

Krzyzanowska, J., Janda, B., Pecio, L., Stochmal, A., Oleszek, W., 2011. Determination of polyphenols in Mentha longifolia and M. piperita field-grown and in vitro plant samples using UPLC-TQ-MS. J. AOAC Int. 94, 43-50.

Kwon, Y., Apostolidis, E., Kim, Y., Shetty, K., 2009. Over-expression of proline-linked antioxidant pathway and modulation of phenolic metabolites in long life span clonal line of Origanum vulgare in response to ultraviolet radiation. J. Food Biochem. 33, 649-673.

Lattanzio, V., Cardinali, A., Ruta, C., Fortunato, I.M., Lattanzio, V.M.T., Linsalata, V., Cicco, N., 2009. Relationship of secondary metabolism to growth in oregano (Origanum vulgare L.) shoot cultures under nutritional stress. Env. Exp. Bot. 65, 54-62.

Lee, E., Moh, S., Paek, K., 2011. Influence of inoculum density and aeration volume on biomass and bioactive compound production in bulb-type bubble bioreactor cultures of Eleutherococcus koreanum Nakai. Bioresource Technol. 102, 71657170 .

Lobo, A.M. and Lourenço, A.M., 2007. Biossíntese de produtos naturais. IST - Instituto Superior Técnico, Lisboa.

Lombardino, J.G., 2000. A brief history of Pfizer Central Research. Bull. Hist. Chem. $25,10$.

Longo, L., Scardino, A., Vasapollo, G., Blando, F., 2007. Anthocyanins from Eugenia myrtifolia Sims. Innov. Food Sci. 8, 329-332.

Lorenzo, J.C., Blanco, M.A., Peláez, O., González, A., Cid, M., Iglesias, A., González, B., Escalona, M., Espinosa, P., Borroto, C., 2001. Sugarcane micropropagation and phenolic excretion. Plant Cell Tiss. Org. Cult. 65, 1-8.

Loyola-Vargas, V. M., and Vázquez-Flota, F. (Eds.), 2006. Plant cell culture protocols (Vol. 318). Totowa, New Jersey: Humana Press. 
Lozovaya, V., Ulanov, A., Lygin, A., Duncan, D., Widholm, J., 2006. Biochemical features of maize tissues with different capacities to regenerate plants. Planta 224, 1385-1399.

Lozovaya, V.V., Gorshkova, T.A., Rumyantseva, N.I., Ulanov, A.V., Valieva, A.I., Yablokova, E.V., Mei, C., Widholm, J.M., 2000. Cell wall-bound phenolics in cells of maize (Zea mays, Gramineae) and buckwheat (Fagopyrum tataricum, Polygonaceae) with different plant regeneration abilities. Plant Sci. 152, 79-85.

Luczkiewicz, M., Kokotkiewicz, A., Glod, D., 2014. Plant growth regulators affect biosynthesis and accumulation profile of isoflavone phytoestrogens in highproductive in vitro cultures of Genista tinctoria. Plant Cell Tiss. Org. 118, 419429.

Lugato, D., Simão, M.J., Garcia, R., Mansur, E., Pacheco, G., 2014. Determination of antioxidant activity and phenolic content of extracts from in vivo plants and in vitro materials of Passiflora alata Curtis. Plant Cell Tiss. Org.118, 339-346.

Madhu, K., 2013. Phytochemical screening and antioxidant activity of in vitro grown plants Clitoria ternatea L., using dpph assay. Asian J. Pharm. Clin. Res., 6, 38-42.

Masoumian, M., Arbakariya, A., Syahida, A., Maziah, M., 2011. Flavonoids production in Hydrocotyle bonariensis callus tissues. J. Med. Plant. Res. 5, 1564-1574.

Matkowski, A., 2008. Plant in vitro culture for the production of antioxidants- A review. Biotechnol. Adv. 26, 548-560.

Mewis, I., Smetanska, I.M., Müller, C.T., Ulrichs, C., 2011. Specific poly-phenolic compounds in cell culture of Vitis vinifera L. cv. Gamay Fréaux. App. Biochem. Biotechol. 164, 148-161.

Michael, J.M. and John, S.F., 1985. Influence of Culture Age and Spermidine Treatment on the Accumulation of Phenolic Compounds in Suspension Cultures. Plant Physiol. 78, 25-28

Muhitch, M.J. and Fletcher, J.S., 1985. Influence of culture age and spermidine treatment on the accumulation of phenolic compounds in suspension cultures. Plant Physiol. 78, 25-28.

Murashige, T. and Skoog, F., 1962. A revised medium for rapid growth and bioassays with tobacco tissue cultures. Physiol. Plant. 15, 473-497.

Murthy, H.N., Georgiev, M.I., Park, S., Dandin, V.S., Paek, K., 2015. The safety assessment of food ingredients derived from plant cell, tissue and organ cultures: A review. Food Chem. 176, 426-432. 
Ncube, B., Ngunge, V.N.P., Finnie, J.F., Van Staden, J., 2011. A comparative study of the antimicrobial and phytochemical properties between outdoor grown and micropropagated Tulbaghia violacea Harv. plants. J. Ethnopharmacol. 134, 775780.

Nishikawa, K., Furukawa, H., Fujioka, T., Fujii, H., Mihashi, K., Shimomura, K., Ishimaru, K., 1999. Flavone production in transformed root cultures of Scutellaria baicalensis Georgi. Phytochemistry. 52, 885-890.

North, J.J., Ndakidemi, P.A., Laubscher, C.P., 2012. Effects of antioxidants, plant growth regulators and wounding on phenolic compound excretion during micropropagation of Strelitzia reginae. Int. J. Phy. Sci. 7, 638-646.

Nunes, J.M., Pinhatti, A.V., Rosa, L.M.G., Poser, G.L., Rech, S.B., 2009. Roles of in vitro plantlet age and growing period in the phenolic constituent yields of acclimatized Hypericum polyanthemum. Env. Exp. Bot. 67, 204-208.

Ozden, M. and Karaaslan, M., 2011. Effects of cytokinin on callus proliferation associated with physiological and biochemical changes in Vitis vinifera L. Acta Physiol. Plantar. 33, 1451-1459.

Palacio, L., Cantero, J.J., Cusidó, R., Goleniowski, M., 2011. Phenolic compound production by Larrea divaricata Cav. plant cell cultures and effect of precursor feeding. Process Biochem. 46, 418-422.

Palacio, L., Cantero, J.J., Cusidóc, R.M., Goleniowski, M.E., 2012. Phenolic compound production in relation to differentiation in cell and tissue cultures of Larrea divaricata (Cav.). Plant Sci. 193-194, 1-7.

Peter, C.H., Howard, T., Ernst, T., 2005. Bringing medicinal plants into cultivation: opportunities and challenges for biotechnology. Trends Biotechnol. 23, 180-185.

Piątczak, E., Grzegorczyk-Karolak, I., Wysokińska, H., 2014. Micropropagation of Rehmannia glutinosa Libosch.: production of phenolics and flavonoids and evaluation of antioxidant activity. Acta Physiol. Plantar. 33, 1693-1702.

Pinhatti, A.V., Nunes, J.M., Maurmann, N., Rosa, L.M.G., von Poser, G.L., Rech, S.B., 2010. Phenolic compounds accumulation in Hypericum ternum propagated in vitro and during plant development acclimatization. Acta Physiol. Plantar. 32, 675-681.

Rady, M.R. and Nazif, N.M., 2005. Rosmarinic acid content and RAPD analysis of in vitro regenerated basil (Ocimum americanum) plants. Fitoterapia 76, 525-533. 
Rao, S.R., Sarada, R., Ravishankar, G.A., 1996. Phycocyanin, a new elicitor for capsaicin and anthocyanin accumulation in plant cell cultures. App. Micro. Biotech. 46, 619-621.

Rea, G., Antonacci, A., Lambreva, M., Pastorelli, S., Tibuzzi, A., Ferrari, S., Fischer, D., Johanningmeier, U., Oleszek, W., Doroszewska, T., Rizzo, A.M., Berselli, P.V.R., Berra, B., Bertoli, A., Pistelli, L., Ruffoni, B., Calas-Blanchard, C., Marty, J.L., Litescu, S.C., Diaconu, M., Touloupakis, E., Ghanotakis, D., Giardi, M.T., 2011. Integrated plant biotechnologies applied to safer and healthier food production: The Nutra-Snack manufacturing chain. Trends Food Sci. Tech. 22, 353-366.

Reis, E.,Batista, M.T.,Canhoto, J.M., 2008. Effect and analysis of phenolic compounds during somatic embryogenesis induction in Feijoa sellowiana Berg. Protoplasma 232, 193-202.

Robbins, W.J., 1922. Cultivation of excised root tips and stem tips under sterile conditions. Bot. gaz. 73, 376-390.

Roberto, T. and Francesca, M., 2011. Sustainable sourcing of natural food ingredients by plant cell cultures. Agro Food Ind. Hi Tech. 22, 26-28.

Roberts, J. A., 2012. Plant growth regulators. Springer Science \& Business Media,

Quideau, S., Deffieux, D., Douat-Casassus, C., Pouységu, L., 2011. Plant polyphenols: chemical properties, biological activities, and synthesis. Angew. Chem. 50, 586621.

Santos-Gomes, P.C., Seabra, R.M., Andrade, P.B., Fernandes-Ferreira, M., 2003. Determination of phenolic antioxidant compounds produced by calli and cell suspensions of sage (Salvia officinalis L.). J. Plant Physiol. 160, 1025-1032.

Savangikar, V. A., 2004. Role of low cost options in tissue culture. Low Costs Options for Tissue Culture Technology in Developing Countries, 11-15.

Schroeder, C., Lutterbach, R., Stöckigt, J., 1996. Preparative biosynthesis of natural glucosides and fluorogenic substrates for $\beta$-glucosidases followed by in vivo $13^{\mathrm{C}}$ NMR with high density plant cell cultures. Tetrahedron 52, 925-934.

Sharan, M., Taguchi, G., Gonda, K., Jouke, T., Shimosaka, M., Hayashida, N., Okazaki, N., 1998. Effects of methyl jasmonate and elicitor on the activation of phenylalanine ammonia-lyase and the accumulation of scopoletin and scopolin in tobacco cell cultures. Plant Sci. 132, 13-19. 
Shetty, K., Carpenter, T.L., Kwok, D., Curtis, O.F., Potter, T.L., 1996. Selection of high phenolics-containing clones of thyme (Thymus vulgaris L.) using Pseudomonas Sp. J. Agri. Food Chem. 44, 3408-3411.

Shimoda, K., Yamane, S., Hirakawa, H., Ohta, S., Hirata, T., 2002. Biotransformation of phenolic compounds by the cultured cells of Catharanthus roseus. J. Mol. Catal. B: Enzym. 16, 275-281.

Shinde, A.N., Malpathak, N., Fulzele, D.P., 2010. Determination of isoflavone content and antioxidant activity in Psoralea corylifolia L. callus cultures. Food Chem. $118,128-132$.

Sinilal, B., Ovadia, R., Nissim-Levi, A., Perl, A., Carmeli-Weissberg, A., Oren-Shamir, M., 2011. Increased accumulation and decreased catabolism of anthocyanins in red grape cell suspension culture following magnesium treatment. Planta 234, 6171.

Sircar, D., Roychowdhury, A., Mitra, A., 2007. Accumulation of p-hydroxybenzoic acid in hairy roots of Daucus carota. J. Plant Physiol. 164, 1358-1366.

Siu, K. and Wu, J., 2014. Enhanced release of tanshinones and phenolics by nonionic surfactants from Salvia miltiorrhiza hairy roots. Eng. Life Sci. 14, 685-690.

Skoog, F. and Miller, C.O., 1957. Chemical regulation of growth and organ formation in plant tissue cultures in vitro. Symp. Soc. Exp. Biol. 11, 118-131.

Skorić, M., Todorović, S., Gligorijević, N., Janković, R., Živković, S., Ristić, M., Radulović, S., 2012. Cytotoxic activity of ethanol extracts of in vitro grown Cistus creticus subsp. creticus L. on human cancer cell lines. Ind. Crop. Prod. 38, 153159.

Smetanska, I., 2008. Production of secondary metabolites using plant cell cultures. Adv. Biochem. Eng. Biotechnol. 111, 187-228.

Stanly, C., Bhatt, A., Ali, A.M.D., Keng, C.L., Lim, B.P., 2011. Evaluation of free radical scavenging activity and total phenolic content in the petiole-derived callus cultures of Zingiber zerumbet Smith. J. Med. Plant. Res. 5, 2210-2217.

Szopa, A. and Ekiert, H., 2012. In Vitro Cultures of Schisandra chinensis (Turcz.) Baill. (Chinese Magnolia Vine) - A potential biotechnological rich source of therapeutically important phenolic acids. App. Biochem. Biotechnol. 166, 19411948. 
Szopa, A. and Ekiert, H., 2014. Production of biologically active phenolic acids in Aronia melanocarpa (Michx.) Elliott in vitro cultures cultivated on different variants of the Murashige and Skoog medium. Plant Growth Regul. 72, 51-58.

Szopa, A., Ekiert, H., Muszyńska, B., 2013. Accumulation of hydroxybenzoic acids and other biologically active phenolic acids in shoot and callus cultures of Aronia melanocarpa (Michx.) Elliott (black chokeberry). Plant Cell Tiss. Org. 113, 323329.

Taveira, M., Pereira, D.M., Sousa, C., Ferreres, F., Andrade, P.B., Martins, A., Pereira, J.A., Valentão, P., 2009. In Vitro cultures of Brassica oleracea L. var. costata DC: potential plant bioreactor for antioxidant phenolic compounds. J. Agric. Food Chem. 57, 1247-1252.

Thiem, B., Kikowska, M., Krawczyk, A., Więckowska, A., Sliwinska, E., 2013. Phenolic acid and DNA contents of micropropagated Eryngium planum L. Plant Cell Tiss. Org. 114, 197-206.

Thiem, B., Wesołowska, M., Skrzypczak, L., Budzianowski, J., 2001. Phenolic compounds in two Solidago L. species from in vitro culture. Acta Pol. Pharm. Drug Res. 58, 277-281.

Ulanov, A., Lygin, A., Duncan, D., Widholm, J., Lozovaya, V., 2009. Metabolic effects of glyphosate change the capacity of maize culture to regenerate plants. J. Plant Physiol. 166, 978-987.

Valdez-Tapia, R., Capataz-Tafur, J., López-Laredo, A.R., Trejo-Espino, J.L., TrejoTapia, G., 2014. Effect of immersion cycles on growth, phenolics content, and antioxidant properties of Castilleja tenuiflora shoots. In Vitro Cell. Dev. B. 50, 471-477.

Verpoorte, R., van der Heijden, R., ten Hoopen, H.J.G., Memelink, J., 1999. Metabolic engineering of plant secondary metabolite pathways for the production of fine chemicals. Biotechnol. Lett. 21, 467-479.

Victório, C.P., Leal-Costa, M.V., Tavares, E.S., Kuster, R.M., Lage, C.L.S., 2011. Effects of supplemental UV-A on the development, anatomy and metabolite production of Phyllanthus tenellus cultured in vitro. Photochem. Photobiol. 87, 685-689.

Vuković, R., Bauer, N., Ćurković-Perica, M., 2013. Genetic elicitation by inducible expression of $\beta$-cryptogein stimulates secretion of phenolics from Coleus blumei hairy roots. Plant Sci. 199-200, 18-28. 
Yang, R. and Shetty, K., 1998. Stimulation of rosmarinic acid in shoot cultures of oregano (Origanum vulgare) clonal line in response to proline, proline analogue, and proline precursors. J. Agric. Food Chem. 46, 2888-2893.

Yang, R., Potter, T.P., Curtis, O.F., Sherry, K., 1997. Tissue culture-based selection of high rosmarinic acid producing clones of rosemary (Rosmarinus officinalis L.) using Pseudomonas strain F. Food Biotechnol. 11, 73-88.

Yang, S., Ubillas, R., McAlpine, J., Stafford, A., Ecker, D.M., Talbot, M.K., Rogers, B., 2001. Three new phenolic compounds from a manipulated plant cell culture, Mirabilis jalapa. J. Nat. Prod. 64, 313-317.

Yildirim, A.B. and Turker, A.U., 2014. Effects of regeneration enhancers on micropropagation of Fragaria vesca L. and phenolic content comparison of fieldgrown and in vitro-grown plant materials by liquid chromatography-electrospray tandem mass spectrometry (LC-ESI-MS/MS). Sci. Hort. 69, 169-178.

Zagoskina, N.V., Alyavina, A.K., Gladyshko, T.O., Lapshin, P.V., Egorova, E.A., Bukhov, N.G., 2005. Ultraviolet rays promote development of photosystem II photochemical activity and accumulation of phenolic compounds in the tea callus culture (Camellia sinensis). Russ. J. Plant Physiol. 52, 731-739.

Zagoskina, N.V., Dubravina, G.A., Alyavina, A.K., Goncharuk, E.A., 2003. Effect of ultraviolet (UV-B) radiation on the formation and localization of phenolic compounds in tea plant callus cultures. Russ. J. Plant Physiol. 50, 270-275.

Zagoskina, N.V., Goncharuk, E.A., Alyavina, A.K., 2007. Effect of cadmium on the phenolic compounds formation in the callus cultures derived from various organs of the tea plant. Russ. J. Plant Physiol. 54, 237-243.

Zhang, W., and Furusaki, S., 1999. Production of anthocyanins by plant cell cultures. Biotechnol. Bioprocess Eng. 4, 231-252.

Zhao, J., Lou, J., Mou, Y., Li, P., Wu, J., Zhou, L., 2011. Diterpenoid tanshinones and phenolic acids from cultured hairy roots of Salvia miltiorrhiza Bunge and their antimicrobial activities. Molecules 16, 2259-2267.

Zhou, L.G. and Wu, J.Y., 2006. Development and application of medicinal plant tissue cultures for production of drugs and herbal medicinals in China. Nat. Prod. Rep. $23,789-810$.

Ziaratnia, S.M., Ohyama, K., Hussein, A.A., Muranaka, T., Lall, N., Kunert, K.J., Meyer, J.J.M., 2009. Isolation and identification of a novel chlorophenol from a 
cell suspension culture of Helichrysum aureonitens. Chem. Pharm. Bull. 57, 1282-1283. 